\title{
Joumal of Agronomy
}

\section{Relationship between polyamines and other cold-induced response mechanisms in different cereal species}

\begin{tabular}{|r|l|}
\hline Journal: & Journal of Agronomy and Crop Science \\
\hline Manuscript ID: & JAC-11-2014-0397.R2 \\
\hline Danuscript Type: & Original article \\
\hline Complete List of Authors: & $\begin{array}{l}\text { Gondor, Kinga; Agricultural Institute, Centre for Agricultural Research, } \\
\text { Hungarian Academy of Sciences, Plant Physiology } \\
\text { Szalai, Gabriella; Agricultural Institute, Centre for Agricultural Research, } \\
\text { Hungarian Academy of Sciences, ; } \\
\text { Kovács, Viktória; Agricultural Institute, Centre for Agricultural Research, } \\
\text { Hungarian Academy of Sciences, Plant Physiology } \\
\text { Janda, Tibor; Agricultural Institute, Centre for Agricultural Research, } \\
\text { Hungarian Academy of Sciences, Department of Plant Physiology } \\
\text { Pál, Magda; Agricultural Institute,Centre for Agricultural } \\
\text { Research, Hungarian Academy of Sciences, Plant Physiology }\end{array}$ \\
\hline Keywords: & \begin{tabular}{l} 
Chilling stress, Crop / stress physiology \\
\hline
\end{tabular} \\
\hline
\end{tabular}


Relationship between polyamines and other cold-induced response mechanisms in different cereal species

Orsolya Kinga Gondor, Gabriella Szalai, Viktória Kovács, Tibor Janda, Magda Pál

Agricultural Institute, Centre for Agricultural Research, Hungarian Academy of Sciences

H-2462 Martonvásár, POB 19.

Tel: $+36-22-569-502$

Fax: $+36-22-569-576$

Corresponding author: pal.magda@agrar.mta.hu

Number of figures: 3

Number of tables: 4 


\section{Abstract}

In order to find a connection between polyamines and various protective effectors involved in the development of cold tolerance, eight different cereal genotypes, including wheat, barley and oat species, were investigated during the acclimation phase to low temperature. Exposure to low temperature induced different changes in the levels of polyamines, and other signalling molecules, such as salicylic acid and abscisic acid, and of other protective compounds, namely flavonols, sugars and antioxidant enzyme activity, and in the lipid composition of certain membrane factions. The most remarkable differences were observed in the oat varieties compared to the other cereal genotypes, which was manifested in the lack of spermidine accumulation and of decrease in trans- $\Delta^{3}$-hexadecanoic acid content, in lower initial and not cold-inducible abscisic acid content and guaiacol peroxidase activity after cold treatment. Correlation analysis revealed that spermidine shows strong positive relationship with flavonols, abscisic acid and ascorbate peroxidase, while was in negative relationship with trans- $\Delta^{3}$-hexadecanoic acid. These results suggest that spermidine may have a crucial role in the cold acclimation signalling processes in cereals.

Key words: cold, polyamines, salicylic acid, abscisic acid, antioxidant enzymes, crop

Abbreviations: ABA: abscisic acid; APX: ascorbate peroxidase; CAT: catalase; DBI: double bond index; DGDG: digalactosyldiacylglycerol; GR: glutathione reductase; GST: glutathioneS-transferase; G-POD: guaiacol peroxidase; MGDG: monogalactosyldiacylglycerol; $o H C A$ : ortho-hydroxy-cinnamic acid; PAs: polyamines; PUT: putrescine; PE: phosphatidylethanolamine; PG: phosphatidylglycerol; SA: salicylic acid; SPD: spermidine; SPN: spermine; 18:2: linoleic acid; 18:3: linolenic acid; 18:1: oleic acid; 16:0: palmitic acid; 18:0: stearic acid; $t 16: 1$ : trans $-\Delta^{3}$-hexadecanoic acid. 


\section{Introduction}

Low temperature may cause injury or reduced growth, depending on the cold tolerance of the plant species. Cold tolerant plants can survive freezing temperature after cold acclimation (Li et al., 2014a). This complex metabolic process involves lipid remodelling, accumulation of compatible solutes or osmolytes: sugars, betaines, amino acids and polyamines, the activation of antioxidant enzymes, and changes in phytohormone levels (Chen et al., 2014; Kosová et al., 2012).

Large body of work shows that polyamines (PAs) are involved in the acquisition of tolerance to abiotic stresses such as low temperature (Gill and Tuteja, 2010). The involvement of PAs in the regulation of various cellular processes, including stress tolerance, may be of general importance. However, the link between individual protective mechanisms and the signalling routes in abiotic stress tolerance are still poorly understood. It is evident that PAs not only play a role as compounds stabilizing macromolecules or as scavengers of reactive oxygen species (ROS), but also function as stress messengers in plant responses to different stress signals (Liu et al., 2007), or also as activators of the expression of genes encoding antioxidant enzymes (Kuznetsov and Shevyakova 2007) and proteins involved in the metabolism of hormones, such as abscisic acid (ABA) or salicylic acid (SA) (Marco et al., 2014).

Transgenic Arabidopsis plants, accumulating high levels of endogenous putrescine (PUT) or spermidine (SPD), achieved by overexpression of arginine decarboxylase or spermidine synthase, showed enhanced tolerance to freezing stress (Kasukabe et al., 2004; Wang et al., 2011). However, when freezing tolerance of Thellungiella sp., was compared with that of certain Arabidopsis accessions, a close relationship was found to exist between the higher freezing tolerance and a smaller pool size of free spermine (SPN) only in Thellungiella, but not in Arabidopsis (Lee et al., 2012). 
The main aim of the present work was to find relationships between the different types of PAs and various stress-related protective effectors in cereals during the low temperature acclimation period. These revealed connections may point out the cross-talk mechanisms in cold response processes. Furthermore, different cereal species (wheat, oat and barley) were compared in order to demonstrate and to reveal the complexity and differences in the different responses of these species to low temperature conditions.

\section{Materials and methods}

\subsection{Plant materials, growth and cold conditions}

Four wheat (Triticum aestivum L.) genotypes, two Thatcher-based near-isogenic lines [TC19, TC33, Cereal Disease Laboratory, USDA (St. Paul, MN, USA)] and two winter wheat varieties (Mv Hombár and Mv 8), together with two spring oat (Avena sativa) varieties (Kwant and Mv Pehely), a winter barley (Hordeum vulgare L.) variety (Petra) and a spring barley (Hordeum vulgare L.) variety (Jubilant) from the Agricultural Institute, Centre for Agricultural Research, Hungarian Academy of Sciences (Martonvásár, Hungary) were used in the present experiments. The seeds (15/ pots) were sown in plastic pots containing $3: 1(\mathrm{v}: \mathrm{v})$ loamy soil and sand, and were grown at $20 / 18^{\circ} \mathrm{C}$ with $16 / 8$-h light/dark periodicity at 250 $\mu \mathrm{mol} \mathrm{m} \mathrm{m}^{-2}$ photon flux density and $75 \%$ relative humidity in a Conviron PGV-36 plant growth chamber (Controlled Environments Ltd, Winnipeg, Canada) in the phytotron of the Agricultural Institute. The plants were grown for $10 \mathrm{~d}$, after which low temperature treatment was carried out in a chamber of the same type at a constant $5^{\circ} \mathrm{C}$. All the leaves were sampled after the $12^{\text {th }}$ day of cold treatment.

\subsection{Polyamine analysis}


After extraction, carried out as described by Németh et al. (2002), PAs were analysed as dansylated derivatives after separation on reverse phase column (Hypersil ODS, 100x2.1 $\mathrm{mm}, 5 \mu \mathrm{m}$, Thermo Scientific) via W474 scanning fluorescence detector (Waters, USA) (excitation: $340 \mathrm{~nm}$; emission: $515 \mathrm{~nm}$ ). Conjugated and bound forms of PAs were measured after 1 hour of acid hydrolyzation at $96^{\circ} \mathrm{C}$.

\subsection{SA, ortho-hydroxy-cinnamic acid (oHCA) and flavonoid extraction and analytical} procedure

SA extraction and analysis were performed according to Pál et al. (2005). After separation on a reverse phase column (ABZ+, 150x4.5 mm, $5 \mu \mathrm{m}$, Supelco, Bellefonte, USA), SA (excitation: $305 \mathrm{~nm}$; emission: $407 \mathrm{~nm}$ ) and oHCA (excitation: $317 \mathrm{~nm}$; emission: 436 nm) were quantified fluorimetrically (W474 fluorescence detector, Waters, USA). Flavonoids were detected with a W996 photodiode array detector (Waters, USA) (rutin, myricetin, quercetin and kaempferol: 230 to $300 \mathrm{~nm}$ ).

\subsection{ABA extraction and analytical procedure}

ABA extraction was performed similarly to SA extraction, while the derivatization method was carried out using N-methyl-N-(tert-butyldimethylsilyl)trifluoroacetamide (Birkemeyer et al., 2003). The analytical analysis was carried out using a Shimadzu Model GC-QP2010 system (Shimadzu Co., Kyoto, Japan) fitted with an SPB-50 capillary column $(30 \mathrm{~m} \times 0.25 \mathrm{~mm}$ I.D., $\mathrm{df}=0.25 \mu \mathrm{m}) \quad($ Supelco/Sigma-Aldrich Co., St. Louis, MO, USA $)$. The injector and initial oven temperatures were 110 and $70^{\circ} \mathrm{C}$, respectively. After the injection, the oven temperature was increased to $250^{\circ} \mathrm{C}$ at a rate of $10^{\circ} \mathrm{C} \min ^{-1}$ and kept at this level for 10 min. Samples were injected in split mode with a 1/10 split ratio. The He carrier flow-rate was 
$1 \mathrm{ml} \mathrm{min}{ }^{-1}$. The ion source temperature was $230^{\circ} \mathrm{C}$ and the solvent cut was 9 min. Quantitative analysis was carried out using SIM mode.

\subsection{Sugar analysis}

$0.5 \mathrm{~g}$ tissue was homogenized in $1 \mathrm{ml}$ distilled water. After centrifugation at $10000 \mathrm{~g}$ for $10 \mathrm{~min}$, the supernatant was incubated for $10 \mathrm{~min}$ at $96^{\circ} \mathrm{C}$. It was then centrifuged at $10000 \mathrm{~g}$ for $10 \mathrm{~min}$ again. After separation on a Supelcosil $\mathrm{LC}-\mathrm{NH}_{2}$ column $(250 \mathrm{x} 4.6 \mathrm{~mm}, 5$ $\mu \mathrm{m}$, Supelco, Bellefonte, USA) under isocratic elution, using 75\% acetonitrile with a $1.4 \mathrm{ml}$ $\min ^{-1}$ flow rate and $34^{\circ} \mathrm{C}$ column temperature, glucose, fructose, sucrose and maltose were quantified using a differential refractometer (W410, Waters, USA) with the following settings: sens.: 512 , scale factor: 20 , internal temperature: $34^{\circ} \mathrm{C}$. For each sample $5 \mu$ was injected. The analysis time was $8 \mathrm{~min}$.

\subsection{Enzyme assays}

The isolation of antioxidant enzyme activity and measurements were performed as described in Pál et al. (2005). The catalase (EC 1.11.1.6.)(CAT) activity of the extract was measured spectrophotometrically by monitoring the decrease in absorbance at $240 \mathrm{~nm}$. The ascorbate peroxidase (EC 1.11.1.11.)(APX) activity was measured by monitoring the decrease in absorbance at $290 \mathrm{~nm}$. The guaiacol peroxidase (EC 1.11.1.7.)(G-POD) activity was determined at $470 \mathrm{~nm}$ and the glutathione reductase (EC 1.6.4.2.)(GR) activity at $412 \mathrm{~nm}$. The glutathione-S-transferase (EC 2.5.1.18.)(GST) activity was measured by monitoring changes in the absorbance at $340 \mathrm{~nm}$.

\subsection{Lipid extraction and fatty acid analysis}


The lipids were extracted as described by Pál et al. (2007) using 1 g leaf samples. The various lipid classes were separated by TLC on silica gel plates, after which the fatty acids were transmethylated. The GC-FID analysis of fatty acid methyl esters (FAME) was carried out using a Shimadzu Model GC-FID2010 system (Shimadzu Co., Kyoto, Japan) fitted with an SP-2380 capillary column $(30 \mathrm{~m} \times 0.25 \mathrm{~mm}$ I.D., $\mathrm{df}=0.20 \mu \mathrm{m})($ Supelco/Sigma-Aldrich Co., St. Louis, MO, USA). In this analysis, the injector and initial oven temperatures were 200 and $175^{\circ} \mathrm{C}$, respectively. After $8 \mathrm{~min}$, the oven temperature was increased to $240^{\circ} \mathrm{C}$ at a rate of $50^{\circ} \mathrm{C} \min ^{-1}$ and kept at this level for $5 \mathrm{~min}$. Samples were injected in split mode with a $1 / 5$ split ratio. The He carrier flow-rate was $37.8 \mathrm{~cm} \mathrm{sec}^{-1}$. Heptadecanoic acid was used as internal standard for the quantification.

The double bond index (DBI) was calculated from the mol\% values using the following formula: DBI $=1 *(\% 18: 1)+2 *(\% 18: 2)+3 *(\% 18: 3)$. The percentage of unsaturation was calculated using the following formula: $\%$ unsat $=(18: 1+18: 2+18: 3) /$ $(16: 0+16: 1+18: 0+18: 1+18: 2+18: 3)$.

\subsection{Statistical analysis}

The results are the means of at least 5 repetitions for both enzyme activity and HPLC or GC analysis. The data were statistically evaluated using the standard deviation and t-test methods. The SPSS 17.0 statistical program was used to examine correlations between the parameters.

\section{Results}

\subsection{Polyamines}

PUT was the most dominant PA form in oat genotypes under control conditions. Only about half this quantity was recorded in barley plants and the lowest PUT level was detected 
in the wheat genotypes, regardless of the growth habit (Fig. 1). The initial SPD content was similar in wheat and oat plants, but lower in the two barley genotypes. The basal SPN content was slightly higher in the wheat varieties than in the other crop species, while the cadaverin level (CAD) was in the same range in wheat and oat plants and in the winter barley, Petra, but was below the detection limit in the spring barley, Jubilant (Fig. 1). The exposure of plants to cold temperature resulted in a substantial increase in PUT. However this increase was less pronounced in barley than in wheat or oat plants. Cold treatment induced the accumulation of SPD in wheat and barley genotypes. In the oat varieties, despite the relatively high basal SPD content, there was only a slight increase or no change after cold treatment (Fig. 1). The pronounced induction of SPN synthesis could be detected in both spring and winter wheat and to an even greater extent in the oat genotypes, while in barley both control and cold-induced SPN levels were low (Fig. 1).

\subsection{Other signalling molecules}

\subsubsection{Salicylic acid and ortho-hydroxy-cinnamic acid}

The basal content of both the free (fSA) and bound form of SA (bSA) was higher in spring wheat compared to the winter wheat varieties (Fig. 2A). The fSA level was slightly lower, the bSA content was approximately 2-fold higher in Kwant than in the other spring oat, Mv Pehely. The winter barley, Petra, contained the highest total SA amount, while in the spring barley, Jubilant, the basal bSA content was similar to that measured in the spring wheat varieties (Fig. 2A).

The fSA content was not changed in any of the genotypes investigated, but significant increases in the bSA level were observed after the cold hardening period in Mv Hombár, Mv8, TC33, Mv Pehely and Jubilant, particularly in the winter wheat varieties and in Mv Pehely. In the spring wheat TC19, the spring oat Kwant, the spring barley Jubilant and 
especially the winter barley Petra, all of which were characterised by a relatively high bSA level even under control growth conditions, no substantial increase was induced by low temperature treatment.

The content of both the free and bound forms of $o \mathrm{HCA}$, which is a putative precursor of SA in certain plants, was the highest in the winter barley variety, Petra (Fig. 2B). In contrast to the other genotypes, the free form of oHCA (foHCA) was below the detection limit in the wheat varieties tested. After exposure to a low temperature, the level of bound $o \mathrm{HCA}(\mathrm{boHCA})$ dramatically increased in all the plants. The pattern of cold-induced changes in boHCA was very similar to that found for bSA (Fig. 2A-B).

\subsubsection{Abscisic acid}

Under control conditions the lowest ABA contents were measured in the oat genotypes, Kwant and Mv Pehely, and in the spring barley Jubilant. After cold there was a dramatic increase in the ABA level in the wheat and barley plants, but it remained low in the oat varieties (Fig. 3).

\subsection{Effector compounds}

\subsubsection{Soluble sugars}

Substantial differences were detected between the 8 genotypes in the initial pattern of the sugar content (Table 1). The basal fructose level was lower in the two TC wheat lines, while the glucose content was higher in the two oat varieties compared to the other genotypes. Sucrose could not be detected in any of the wheat lines under control growth condition and maltose only in lines TC33. In almost all cases significant increases were observed after cold treatment in the sugar content. Higher total accumulation was found in the oat and barley 
plants; however, the initial total sugar content was also higher in these genotypes regardless of the growth type.

\subsubsection{Flavonoids}

The most abundant flavonoid was quercetin, both in the free and bound forms, kaempferol was below the detection limit in all the genotypes tested. The greatest accumulation after cold treatment was usually also detected for quercetin, although these changes were not statistically significant for either the free or bound form in winter barley genotype Petra or for the bound form in winter wheat variety Mv8 and spring oat variety Kwant. In the oat genotype Mv Pehely, while the bound form of quercetin significantly increased, its free form decreased (Table 1). Exposure to low temperature also increased the level of rutin in most cases, and that of myricetin in the genotypes Mv Hombár, Mv 8, TC19 and Jubilant.

\subsubsection{Antioxidant enzymes}

Although all the genotypes responded similarly to cold treatment, several notable differences could be detected in the basal pattern of antioxidant enzyme activity. The initial activities of GR, GST and CAT were lower in the two barley genotypes, while lower G-POD activity was measured in the two oat varieties compared to the other genotypes (Table 1). Cold treatment induced the activity of GR, GST, CAT and APX, but decreased that of the GPOD enzyme. The greatest changes occurred in the CAT activity of the barley varieties, where, in spite of their low initial activity, the cold-hardened values were similar to those found in the other cereal genotypes.

\subsection{Fatty acid composition}


The following lipid fractions were presented here: monogalactosyldiacylglycerol (MGDG), digalactosyldiacylglycerol (DGDG), phosphatidylethanolamine (PE) and phosphatidylglycerol (PG).

In the galactolipid fractions (MGDG and DGDG) the proportion of polyunsaturated linolenic acid (18:3) was so high in the control plants $(89-96 \%$ for MGDG and $82-86 \%$ for DGDG) that was not influenced by the cold treatment. Accordingly, the percentage of unsaturation and the DBI of the MGDG and DGDG fractions did not change after cold stress (Table 2).

In the phospholipid PE fraction relatively high initial unsaturation was found in the two spring wheat (TC33 and TC19), the two spring oat (Kwant and Mv Pehely) and the winter barley genotype, Petra. Cold treatment resulted in a significant decrease in the proportion of palmitic acid (16:0) in Mv Hombár, and less pronounced decreases in the wheat lines Mv8 and TC19 and in the spring barley Jubilant. Significant decrease was observed in the level of stearic acid (18:0) in the wheat genotypes Mv Hombár and TC33, and in linoleic acid (18:2) amount in TC19 and TC33 after cold treatment. An increased proportion of 18:3 was found after cold treatment, except in Kwant (spring oat) and Petra (winter barley). These changes resulted in a significant increment in the DBI of the four wheat genotypes and the spring barley Jubilant.

Control plants of the two winter wheat varieties (Mv Hombár and Mv 8) and the winter barley Petra showed greater unsaturation in the phospholipid PG fraction due to the higher proportion of 18:3, while the five spring cereal genotypes had a lower basal unsaturation level (Table 2). Cold treatment significantly increased the DBI in the two winter wheat genotypes, in the spring wheat TC33 and in the spring oat Mv Pehely, while a decrease was observed in the case of the winter barley Petra. These differences can be attributed to the different changes in the fatty acid composition. The level of saturated 16:0 significantly 
increased in all the genotypes with the exception of the spring oat Mv Pehely and the spring wheat TC33, while the amount of another saturated fatty acid, 18:0, significantly increased in the winter barley Petra and the spring barley Jubilant. In contrast, the proportion of trans- $\Delta^{3}-$ hexadecanoic acid (t16:1), which was only detectable in the PG fraction, decreased significantly in all the genotypes except for the two spring oats (Table 2). The level of 18:3 increased in the spring wheat TC33 and in the spring oat Mv Pehely, but decreased in the winter barley Petra.

\subsection{Correlation analysis}

Significant, close correlations between the investigated parameters under control and cold conditions are highlighted in Tables 3 and 4, respectively. The correlation patterns differed to some extent after cold treatment compared to control conditions. Under control conditions the bSA content showed a positive correlation with the $o$ HCA level. Both bSA and boHCA were in positive relation with $\mathrm{CAD}$, but foHCA was in negative correlation with SPD. bSA and $o$ HCA showed a positive relationship with the sugar content in several cases, especially with maltose, and, among the flavonoids, with the bound rutin and free myricetin contents. Other sporadically occurring relationships were also detected (Table 3).

The most pronounced changes in the pattern of the correlation coefficient values after cold treatment (Table 4) were found in the case of SPD and flavonoids. After cold treatment SPD was found to be in positive correlation with all the bound flavonoids and free quercetin, $\mathrm{ABA}$ levels and in negative relationship with the amount of $t 16: 1$. Flavonoids were found to be in positive correlation both with boHCA content and with APX and G-POD activity. Interestingly, after cold treatment the level of ABA also showed positive correlation with the level of bound rutin and myricetin, while it was in negative relationship with that of $t 16: 1$. t16:1 showed a negative relationship with APX and G-POD activities. 


\section{Discussion}

The impact of cold treatment on the levels of several compounds such as the plant hormones, stress protective compounds as sugars, flavonoids or polyamines, antioxidant activities, and changes in lipid compositions during the cold acclimation period has been reported. Furthermore relationship between these compounds and cold tolerance was found (Szalai et al., 2001; Zhang et al., 2009; Gould and Lister, 2010; Nägele et al., 2011; Kosová et al., 2012; Pál et al., 2013). Most of the results describing cold acclimation mechanisms are achieved using different plant species, especially model plant Arabidopsis. However, these results cannot be generalised, even in closely related species, where different metabolites may have important roles. Present results also show that relatively closely related cereal species showed significantly different responses to exposure to low temperatures.

PAs, besides their direct protective role, also act as antioxidants or signalling molecules especially under stress conditions. PAs activate the expression of genes encoding antioxidant enzymes (Kuznetsov and Shevyakova 2007) and genes involved in hormone metabolism (Marco et al., 2014). Transgenic plants accumulating higher levels of endogenous PUT or SPD showed enhanced resistance to multiple environmental stresses (Kasukabe et al., 2004; Wang et al., 2011). However, close relationship has been found between the higher freezing tolerance and a lower pool size of free SPN in Thellungiella, but not in Arabidopsis (Lee et al., 2012). In the present experiment the initial PUT content was low in wheat varieties, but its synthesis was induced at low temperature, especially in winter varieties, while in oat and barley genotypes, which have higher basal contents, the accumulation after cold treatment was relatively low. The fact that low-temperature stress may also lead to an increased PUT level in chilling-sensitive plants (Németh et al., 2002) suggests that the PUT level is not directly related to cold tolerance but are part of a general adaptation process. 
Although wheat and oat plants had similar initial SPD contents, greater accumulation in response to cold was found in wheat plants, followed by the two barley varieties, irrespective of the growth type. Cold treatment did not influence the SPN level in barley plants, again regardless of the growth type. These results suggest that the magnitude of changes in PA contents during cold treatment is more related to the genetic background than to winter and spring growth habit of the plants.

Role of PUT in cold acclimation process of Arabidopsis is at least in part mediated through the regulation of ABA biosynthesis (Cuevas et al., 2008). ABA dependent signalling and transcriptional regulation is necessary, but not sufficient for successful cold acclimation, as not all genes induced by low temperature are ABA dependent (Theocharis et al. 2012; Li et al., 2014b). The genes involved in SPD and SPN synthesis have been found to be regulated both by abiotic stress but also by ABA treatment (Jiménez-Bremont et al., 2007). In the present study a similar basal ABA level was detected in the wheat plants and in winter barley, while the ABA content increased after cold treatment in all the genotypes except for the two spring oat varieties. Although spring barley had the lowest initial ABA content, it exhibited the highest cold-induced accumulation. Correlation analysis showed a positive relationship between ABA and SPD under cold conditions. Close relationship between PAs, especially SPD and chilling tolerance has been also reported in bean (Guye et al., 1986) and rice (Lee, 1997). In the present experiment PUT content increased in all genotypes, but the SPD content showed remarkable increase only in those genotypes where ABA level increased after cold treatment. Similarly, PUT and SPD increased under cold treatment in the wild type tomato plants; whereas only PUT was augmented in the ABA-deficient tomato plants (Kim et al., 2002).

The role of SA and related compounds in acclimation processes to low temperatures has been demonstrated (Sasheva et al., 2013). SA treatment influences PA content (Németh et 
al., 2002) and catabolism (Szepesi et al., 2011); and exogenous PAs also induce changes in SA level (Iqbal et al., 2006). Thus, a relationship is thought to exist between endogenous SA and PA contents under abiotic stress conditions (Kovács et al., 2014). In addition, relationship between SA and ABA has also been reported (Pál et al., 2011). In the present experiment cold treatment increased the bSA content in genotypes with lower initial content (winter wheat: Mv Hombár, Mv 8, spring wheat: TC33, spring oat: Mv Pehely and spring barley: Jubilant). The boHCA level increased in all the genotypes, with a higher increment in wheat plants, regardless of the growth type. Since oHCA has been demonstrated to have antioxidant properties (Foley et al., 1999), it may play an antioxidative role in the response to cold. Positive correlation was found between CAD and bSA or boHCA under control growth conditions.

The putative physiological functions of flavonoids include ROS scavenging, functioning as a carbon sink under cold conditions, and having a direct effect on membrane stability (Korn et al., 2008). PAs conjugated with phenolic compounds appear to be more efficient scavengers than the free forms; in other words polyamines may enhance the antioxidant activities of other molecules by making conjugates (Velikova et al., 2007). Although increased flavonoid contents were reported after PAs treatment both under normal conditions (Ali et al., 2007) and under salt stress (Ghosh et al., 2012), their relationships with PAs have not yet been extensively studied. In the present experiment correlation was found between the SPD or ABA contents and flavonoid levels under cold condition. This finding is in agreement with earlier report, where PAs and ABA treatments increased the activity of phenylalanine ammonia-lyase, one of the key enzymes in the synthesis of flavonoids (Hao et al., 2012). Majority of flavonols are also positively correlated with the highly cold-induced boHCA level, and APX activity. These results suggest that low temperature do not 
specifically induce certain flavonol forms, but the whole phenolic synthesis pathway is activated; and these may be part of the whole redox regulation system.

Although freezing tolerance has been connected with changes in certain soluble carbohydrates during cold hardening (Galiba et al., 2002), correlation between freezing tolerance and soluble sugar levels is not always evident (Lee et al., 2012). Under the present conditions, the wheat genotypes had lower initial sugar content than the other species, while the highest total sugar accumulation after cold treatment was found in barley varieties, regardless of the growth type. Exogenous polyamine treatments have been reported to enhance the accumulation of soluble sugars (Shi et al., 2013). Acclimated freezing tolerance was correlated with sucrose levels in Arabidopsis and Thellungiella plants, while it was negatively correlated with SPN content only in Thellungiella plants (Lee et al., 2012). Although low temperature generally increased the levels of both PAs and soluble sugars in the present experiment, negative correlation was found between SPN and glucose, sucrose or maltose under control conditions, between SPD and glucose or sucrose, and SPN and sucrose after cold treatment.

Exposure to low temperature increases the amount of ROS not only in cold sensitive, but also in cold-tolerant plants. During investigation on frost-tolerant and frost-sensitive cereal species correlation between the enzyme activity and the frost tolerance was found in the case of G-POD and APX from hardened leaves but not in the crowns or in the unhardened leaves (Janda et al., 2003). In the present study barley varieties could be characterised with relatively low basal GR, GST and CAT, and spring oat plants with very low G-POD activities. G-POD activity did not change significantly in winter wheat and winter barley varieties, but decreased in spring wheat and spring barley genotypes after cold treatment. Our experiments showed positive correlation between PUT or SPD and GR, between SPD and APX, and between SPN and GR, CAT and APX, respectively under cold conditions. Low 
temperature also induced the synthesis of another PA, cadaverine, which is synthesized independently from the PUT-SPD-SPN pathway and is thought to act as a free radical scavenger (Szalai et al., 2009). The higher levels of PAs positively correlated with the induced antioxidants, so PAs accumulation is able to optimize the metabolic rate and subsequently ensuring the growth and survival of the plant under stress conditions.

The cold hardening of cereals caused changes in the PG lipid fraction, which contribute to maintaining the thylakoid membrane organization of proteins and pigments and the optimal conformation of the D1 protein, stabilizing the photosystem complexes, and facilitating efficient linear electron flow (Kruse et al., 2000). A strong direct relationship between freezing tolerance and the capacity to change the $t 16: 1$ content of PG in response to low temperature could be observed in cereals (Szalai et al., 2001). In the present experiment a close, negative relationship could be detected between $t 16: 1$ and the levels of SPD, ABA, APX, G-POD and rutin. However, the cold-induced drop in the $t 16: 1$ content of PG could not usually be observed in various cold-tolerant dicotyledonous species (Huner et al., 1989) and similar changes have been shown in cold-sensitive maize plants exposed to the heavy metal cadmium (Pál et al., 2007), it appears that this effect is not the main factor in freezing tolerance, but rather a general stress response. The strong negative correlation between $t 16: 1$ and APX or G-POD is in accordance with the correlation between the frost tolerance of cereals and decrease in t16:1 (Szalai et al., 2001) and with increase in APX and G-POD (Janda et al., 2003) during the cold hardening period. Present results suggest that among the PAs SPD, and among the flavonols rutin may have a special role in the cold acclimation processes in cereals.

The exposure of chickpea plants to low temperatures increased the DBI, while ABA treatment alone caused hardly any change of this parameter at any time during the cold hardening period. When the two treatments were applied together the effect was synergistic 
(Bakht et al., 2006). It should also be mentioned that the SPD and SPN contents were in significant positive correlation with the DBI in PG under cold conditions, suggesting the possible regulatory role of PAs in the lipid metabolism. However, this hypothesis will need to be confirmed by further experiments.

In conclusion, significant differences were found in the pattern of the cold-responsive compounds in the different crop species. The most remarkable differences were observed in the spring oat varieties compared to the other cereal genotypes. These were manifested in the lack of SPD accumulation and of decrease in t16:1 content, in lower initial and not coldinducible ABA content and peroxidase activity after cold treatment. Low temperature does not only induce flavonol accumulation, but the whole phenolic synthesis pathway is activated, which process may be part of the whole redox regulation system. Cross-talk exists between PAs and various stress-related protective mechanisms in cereals at low temperature. Strong relationship of SPD with flavonols, ABA, $t 16: 1$ and APX suggest that among PAs SPD may play a crucial role in the cold acclimation signalling processes in cereals.

\section{Acknowledgements}

This work was supported by a grant from the Hungarian National Scientific Research Foundation (OTKA 108811).

\section{References}

Ali, R.M., H.M., Abbas, and R.K., Kamal, 2007: The effects of treatment with polyamines on dry matter, oil and flavonoid contents in salinity stressed chamomile and sweet marjoram. Plant Soil Environ. 53, 529-543. 
Bakht, J., A., Bano, and P., Dominy, 2006: The role of abscisic acid and low temperature in chickpea (Cicer arietinum) cold tolerance. II. Effects on plasma membrane structure and function. J. Exp. Bot. 57, 3707-3715.

Birkemeyer, C., A., Kolasa, and J., Kopka, 2003: Comprehensive chemical derivatization for gas chromatography-mass spectrometry-based multi-targeted profiling of the major phytohormones. J. Chrom. A, 993, 89-102.

Chen, L.J., H.Z., Xiang, Y., Miao, L., Zhang, Z.F., Guo, X.H., Zhao, J.W., Lin and T.L. Li, 2014: An overview of cold resistance in plants. J. Agron. Crop Sci. 200, 237-245.

Cuevas, J.C., R., López-Cobollo, R., Alcázar, R., Zarza, C., Koncz, and T., Altabella, 2008: Putrescine is involved in Arabidopsis freezing tolerance and cold acclimation by regulating ABA levels in response to low temperature. Plant Physiol. 148, 1094-1105.

Foley, S., S., Navaratnam, D.J., McGarvey, E.J., Land, G., Truscott, and C.A., Rice-Evans, 1999: Singlet oxygen quenching and the redox properties of hydroxycinnamic acids. Free Radic. Biol. Med. 26, 1202-1208.

Galiba, G., G., Kocsy, I., Kerepesi, A., Vágújfalvi, L., Cattivelli, and J., Sutka, 2002: Plant Cold Hardiness: Gene Regulation and Genetic Engeneer, Involvement of glutathione and carbohydrate biosynthesis moreover cor14b gene expression in wheat cold acclimation. Kluwer Academic/Plenum Publishers, New York.

Ghosh, N, S.P., Das, C., Manda, S., Gupta, K., Das, N., Dey, and M.K., Adak, 2012: Variations of antioxidative responses in two rice cultivars with polyamine treatment under salinity stress. Physiol. Mol. Biol. Plants, 18, 301-313.

Gill, S.S., and N., Tuteja, 2010: Polyamines and abiotic stress tolerance in plants. Plant Signal Behav. 5, 26-33.

Gould, K.S., and C., Lister, 2006: Flavonoid functions in plants, Flavonoids: chemistry, biochemistry and applications. CRC Press LLC. Boca Raton (UK). 
Guye, M.G., L., Vigh, and J.M., Wilson, 1986: Polyamine titre in relation to chillingsensitivity in Phaseolus sp. J. Exp. Bot. 37, 1036-1043.

Hao, G., H., Ji, Y., Li, R., Shi, J., Wang, L., Feng, L., Huang, 2012: Exogenous ABA and polyamines enhanced salvianolic acids contents in hairy root cultures of Salvia miltiorrhiza Bge. f. alba Plant OMIC Journal 5, 446-452.

Huner, N.P.A., J.P., Williams, E.E., Maissan, E.G., Myscich, M., Krol, A., Laroche, and J., Singh, 1989: Low temperature-induced decrease in trans- $\Delta^{3}$-hexadecenoic acid content is correlated with freezing tolerance in cereals. Plant Physiol. 89, 144-150.

Iqbal, M., M., Ashraf, A., Jamil, and S., Rehman, 2006: Does seed priming induce changes in the levels of some endogenous plant hormones in hexaploid wheat plants under salt stress? J. Int. Plant Biol. 48, 181-189.

Janda, T., Szalai, G., Rios-Gonzalez, K., Veisz, O., and Páldi, E., 2003: Comparative study of frost tolerance and antioxidant activity in cereals. Plant Sci. 164, 301-306.

Jiménez-Bremont, J.F., O.A., Ruiz, and M., Rodríguez-Kessler, 2007: Modulation of spermidine and spermine levels in maize seedlings subjected to long-term salt stress. Plant Physiol. Biochem. 45, 812-21.

Kasukabe, Y., L., He, K., Nada, S., Misawa, I., Ihara, and S., Tachibana, 2004: Overexpression of spermidine synthase enhances tolerance to multiple environmental stresses and up-regulates the expression of various stress-regulated genes in transgenic Arabidopsis thaliana, Plant Cell Physiol. 45, 712-722.

Kim, T.E., S.K., Kim, T.J., Han, J.S., Lee, and S.C., Chang, 2002: ABA and polyamines act independently in primary leaves of cold-stressed tomato (Lycopersicon esculentum). Physiol. Plantarum, 115, 370-376.

Korn, M., S., Peterek, H.P., Mock, A.G., Heyer, and D.K., Hincha, 2008: Heterosis in the freezing tolerance, and sugar and flavonoid contents of crosses between Arabidopsis 
thaliana accessions of widely varying freezing tolerance. Plant, Cell Environ. 31, 813827.

Kosová, K., I. T., Prášil, P., Vítámvás, P., Dobrev, V., Motyka, K., Floková, O., Novák, V., Turečková, J., Rolčik, B., Pešek, A., Trávničková, A., Gaudinová, G., Galiba, T., Janda, E., Vlasáková, P., Prášilová, and R., Vanková, 2012: Complex phytohormone responses during the cold acclimation of two wheat cultivars differing in cold tolerance, winter Samanta and spring Sandra. J. Plant Physiol. 169, 567-576.

Kovács, V., O.K., Gondor, G., Szalai, I.. Majláth, T., Janda, and M., Pál, 2014: UV-B radiation modifies the acclimation processes to drought or cadmium in wheat. Environ. Exp. Bot. 100, 122-131.

Kruse, O., B., Hankamer, C., Konczak, C., Gerle, E., Morris, A., Radunz, G.H., Schmid, and J., Barber, 2000: Phosphatidylglycerol is involved in the dimerization of photosystem II. J. Biol. Chem. 275, 6509-6514.

Kuznetsov, V.V., and N., Shevyakova, 2007: Polyamines and stress tolerance of plants. Plant Stress 1, 50-71.

Lee, T.M., H.S., Lur, and C., Chu, 1997: Role of abscisic acid in chilling tolerance of rice (Oryza sativa L.) seedlings: II. Modulation of free polyamine levels. Plant Sci. 126, 110.

Lee, Y.P., A., Babakov, B., de Boer, E., Zuther, and D.K., Hincha, 2012: Comparison of freezing tolerance, compatible solutes and polyamines in geographically diverse collections of Thellungiella sp. and Arabidopsis thaliana accessions. BMC Plant Biology, 12, 131.

Li, X., J. Cai, F. Liu, T. Dai, W. Cao, and D. Jiang, 2014a: Spring freeze effect on wheat yield is modulated by winter temperature fluctuations: evidence from meta-analysis and simulating experiment. . J. Agron. Crop Sci. DOI: 10.1111/jac.12115 
Li, X., J., Cai, F., Liu, T., Dai, W., Cao and D., Jiang, 2014b: Exogenous abscisic acid application during grain filling in winter wheat improves cold tolerance of offspring's seedlings. J. Agron. Crop Sci. DOI: 10.1111/jac.12064

Liu, J.H., H., Kitashiba, J., Wang, Y., Ban, and T., Moriguchi, 2007: Polyamines and their ability to provide environmental stress tolerance to plants. Plant Biotech. 24, 117-126.

Marco, F., R., Alcázar, A.F., Tiburcio, and Carrasco, P., 2011: Interactions between polyamines and abiotic stress pathway responses unraveled by transcriptome analysis of polyamine overproducers. OMICS $15,775-781$.

Nägele, T., B.A., Kandel, S., Frana, M., Meißner, and A.G., Heyer, 2011: A systems biology approach for the analysis of carbohydrate dynamics during acclimation to low temperature in Arabidopsis thaliana. FEBS Journal 278, 506-518.

Németh, M., T., Janda, E., Horváth, E., Páldi, and G., Szalai, 2002: Exogenous salicylic acid increases polyamine content but may decrease drought tolerance in maize. Plant Sci. $162,569-574$.

Pál, M., E., Horváth, T., Janda, E., Páldi, and G., Szalai, 2005: Cadmium stimulates the accumulation of salicylic acid and its putative precursors in maize (Zea mays L.) plants. Physiol. Plant., 125, 356-364.

Pál, M., O.K., Gondor, and T., Janda, 2013: Role of salicylic acid in acclimation to low temperature. Acta Agron. Hung. 61, 161-172.

Pál, M., Janda, T., Szalai, G., 2011: Abscisic Acid May Alter the Salicylic Acid-Related Abiotic Stress Response in Maize. J. Agron . Crop Sci. 197, 368-377.

Pál, M., N., Leskó, T., Janda, E., Páldi, G., Szalai, 2007: Cadmium-induced changes in the membrane lipid composition of maize plants. Cereal Res. Comm. 35, 1631-1642. 
Sasheva, P., R., Yordanova, T., Janda, G., Szalai, and L., Maslenkova, 2013: Study of primary photosynthetic reactions in winter wheat cultivars after cold hardening and freezing. Effect of salicylic acid. Bulg. J. Agric. Sci. 19, 45-48.

Shi, H., T. Ye, Z. Chan, 2013: Comparative proteomic and physiological analyses reveal the protective effect of exogenous polyamines in the bermuda grass (Cynodon dactylon) response to salt and drought stresses. J. Proteome Res. 12, 4807-4829.

Szalai, G., M., Pap, and T., Janda, 2009: Light-induced frost tolerance differs in winter and spring wheat plants. J. Plant Physiol. 166, 1826-1831.

Szalai, G., T., Janda, E., Páldi, and J.P., Dubacq, 2001: Changes in the fatty acid unsaturation after hardening in wheat chromosome substitution lines with different cold tolerance. J. Plant Physiol. 158, 663-666.

Szepesi, Á., K., Gémes, G., Orosz, A., Pető, Z., Takács, and M., Vorák, 2011: Interaction between salicylic acid and polyamines and their possible roles in tomato hardening processes. Acta Biol. Szeged. 55, 165-166.

Theocharis, A., C., Clément, and E.A., Barka, 2012: Physiological and molecular changes in plants grown at low temperatures. Planta. 235, 1091-1105.

Velikova, V.B., A.M., Edreva, T.D., Tsonev, and H.G., Jones, 2007: Singlet oxygen quenching by phenylamides and their parent compounds, Z. Naturforsch. 62c, 833838.

Wang, B.Q., Q.F., Zhang, J.H., Liu, and G.H., Li, 2011: Overexpression of PtADC confers enhanced dehydration and drought tolerance in transgenic tobacco and tomato: Effect on ROS elimination, Biochem. Biophys. Res. Commun. 413, 10-16.

Zhang, W., B., Jiang, W., Li, H., Song, Y., Yu, and J., Chen. 2009: Polyamines enhance chilling tolerance of cucumber (Cucumis sativus L.) through modulating antioxidative system. Scientia Horticulturae. 122, 200-208. 
Table 1. Effect of cold treatment on the activity of glutathione reductase, glutathione-S-transferase, catalase, ascorbate peroxidase and guaiacol peroxidase, and on the levels of fructose, glucose, sucrose, maltose, rutin, myricetin and quercetin in the leaves of winter wheat (Mv Hombár and Mv8), spring wheat (TC33 and TC19) spring oat (Kwant and Mv Pehely), winter barley (Petra) and spring barley (Jubilant). Data represent mean values \pm SD; *, ** and *** denote significant differences from control at the $0.05,0.01$ and 0.005 levels, respectively $(\mathrm{n}=3)$.

\begin{tabular}{|c|c|c|c|c|c|c|c|c|c|}
\hline $\begin{array}{l}\text { activity/amount } \\
\left(\mathrm{g}^{-1} \mathrm{FW}\right)\end{array}$ & treatment & Mv Hombár & Mv 8 & TC33 & TC19 & Kwant & Mv Pehely & Petra & Jubilant \\
\hline \multirow[t]{2}{*}{ GR nkat } & control & $59.2 \pm 3.3$ & $46.2 \pm 5.8$ & $45.9 \pm 5.8$ & $48.8 \pm 3.3$ & $51 \pm 0.4$ & $51.3 \pm 2.3$ & $30.3 \pm 4.9$ & $28 \pm 3.6$ \\
\hline & cold & $63.7 \pm 3.7$ & $57.5 \pm 0.5^{* *}$ & $57.0 \pm 3.9^{*}$ & $57.5 \pm 3.6^{*}$ & $65.4 \pm 4.2 * * *$ & $60.2 \pm 7$ & $46.9 \pm 5.6 * *$ & $44.5 \pm 1.1 * * *$ \\
\hline \multirow[t]{2}{*}{ GST nkat } & control & $5.9 \pm 1$ & $5.3 \pm 1.2$ & $5.9 \pm 1.6$ & $6.6 \pm 0.2$ & $8.7 \pm 0.8$ & $11 \pm 0.1$ & $2.1 \pm 0.7$ & $2.5 \pm 0.3$ \\
\hline & cold & $7.8 \pm 1$ & $7.3 \pm 0.2 *$ & $8.6 \pm 0.6$ & $10 \pm 0.5^{* * *}$ & $13.6 \pm 0.5 * * *$ & $15.1 \pm 0.6^{* * *}$ & $5.7 \pm 0.9 * * *$ & $5.5 \pm 2.1$ \\
\hline \multirow[t]{2}{*}{ CAT nkat } & control & $7740 \pm 1039$ & $6163 \pm 1522$ & $4515 \pm 1580$ & $6670 \pm 1622$ & $7903 \pm 832$ & $8161 \pm 1082$ & $1956 \pm 172$ & $3373 \pm 1167$ \\
\hline & cold & $10536 \pm 364 * * *$ & $9011 \pm 1415$ & $8385 \pm 165^{* *}$ & $8944 \pm 668$ & $9159 \pm 724$ & $9365 \pm 1004$ & $7621 \pm 949 * * *$ & $8261 \pm 796 * * *$ \\
\hline \multirow[t]{2}{*}{ APX nkat } & control & $91 \pm 15$ & $113 \pm 18.9$ & $95.9 \pm 7.9$ & $95.9 \pm 18.9$ & $77.2 \pm 7.7$ & $66.4 \pm 4.1$ & $60 \pm 11.7$ & $98.8 \pm 8.4$ \\
\hline & cold & $167 \pm 19.9 * * *$ & $152 \pm 2.3 * *$ & $160 \pm 20.9 * * *$ & $139 \pm 6.3 * *$ & $100 \pm 8.1 * *$ & $98.3 \pm 8.2 * * *$ & $103 \pm 15.6^{* * *}$ & $118 \pm 25.5$ \\
\hline \multirow[t]{2}{*}{ POD nkat } & control & $339 \pm 51.8$ & $368 \pm 56.6$ & $443 \pm 6.6$ & $446 \pm 15.9$ & $116 \pm 2.2$ & $100 \pm 20.8$ & $416 \pm 43.1$ & $489 \pm 42.6$ \\
\hline & cold & $359 \pm 57.5$ & $291 \pm 33.2$ & $331 \pm 33.7 * *$ & $237 \pm 34.9 * * *$ & $65.2 \pm 8.9 * * *$ & $73.8 \pm 12.8$ & $263 \pm 104$ & $352 \pm 67 *$ \\
\hline \multirow[t]{2}{*}{ free rutin $\mu \mathrm{g}$} & control & $0.7 \pm 0.1$ & $0.4 \pm 0.04$ & $0.3 \pm 0.2$ & $0.5 \pm 0.0$ & $0.02 \pm 0.0$ & $0.1 \pm 0.07$ & $0.3 \pm 0.03$ & $0.2 \pm 0.03$ \\
\hline & cold & $1.1 \pm 0.3$ & $0.6 \pm 0.2$ & $0.5 \pm 0.1$ & $0.9 \pm 0.06^{* * *}$ & $0.02 \pm 0.01$ & $0.3 \pm 0.04 * *$ & $0.6 \pm 0.2 *$ & $0.6 \pm 0.05 * * *$ \\
\hline \multirow[t]{2}{*}{ free myricetin $\mu \mathrm{g}$} & control & $0.1 \pm 0.01$ & $0.1 \pm 0.05$ & $0.1 \pm 0.01$ & $0.1 \pm 0.02$ & $0.06 \pm 0.0$ & $0.1 \pm 0.02$ & $0.2 \pm 0.04$ & $0.1 \pm 0.01$ \\
\hline & cold & $0.1 \pm .03 * *$ & $0.1 \pm 0.02$ & $0.1 \pm 0.03$ & $0.1 \pm 0.0$ & $0.03 \pm 0.0$ & $0.04 \pm 0.0$ & $0.2 \pm 0.04$ & $0.3 \pm 0.01 * * *$ \\
\hline \multirow[t]{2}{*}{ free quercetin $\mu \mathrm{g}$} & control & $1.4 \pm 0.2$ & $1.2 \pm 0.3$ & $0.8 \pm 0.2$ & $1.3 \pm 0.3$ & $1.7 \pm 0.30$ & $1.2 \pm 0.3$ & $1.2 \pm 0.2$ & $0.9 \pm 0.2$ \\
\hline & cold & $2.7 \pm 0.3 * * *$ & $2.3 \pm 0.5 * *$ & $3.4 \pm 0.3 * * *$ & $3.1 \pm 0.5 * * *$ & $2.5 \pm 0.1 * *$ & $0.3 \pm 0.1 * * *$ & $0.9 \pm 0.2$ & $2.4 \pm 0.05 * * *$ \\
\hline \multirow[t]{2}{*}{ bound rutin $\mu \mathrm{g}$} & control & $0.2 \pm 0.04$ & $0.2 \pm 0.05$ & $0.2 \pm 0.1$ & $0.3 \pm 0.1$ & $0.5 \pm 0.1$ & $0.4 \pm 0.1$ & $0.9 \pm 0.08$ & $0.2 \pm 0.07$ \\
\hline & cold & $3.2 \pm 0.1 * * *$ & $4 \pm 0.3 * * *$ & $3.1 \pm 0.1 * * *$ & $3.6 \pm 0.7 * * *$ & $1.2 \pm 0.6$ & $1.9 \pm 0.2 * *$ & $2.9 \pm 0.8 * *$ & $2.9 \pm 0.4 * * *$ \\
\hline \multirow[t]{2}{*}{ bound myricetin $\mu \mathrm{g}$} & control & $0.9 \pm 0.4$ & $0.9 \pm 0.2$ & $2.2 \pm 0.6$ & $1.5 \pm 0.5$ & $0.9 \pm 0.2$ & $0.4 \pm 0.2$ & $1.1 \pm 0.5$ & $0.5 \pm 0.1$ \\
\hline & cold & $5 \pm 0.4 * * *$ & $5.6 \pm 0.4^{* * *}$ & $2.8 \pm 0.1$ & $4.9 \pm 0.4 * * *$ & $0.6 \pm 0.2$ & $1.1 \pm 0.5$ & $0.7 \pm 0.2$ & $4 \pm 1.3 * * *$ \\
\hline \multirow[t]{2}{*}{ bound quercetin $\mu \mathrm{g}$} & control & $16.1 \pm 2.9$ & $30.7 \pm 10.8$ & $9.7 \pm 3.1$ & $10.6 \pm 3.1$ & $17.8 \pm 5.3$ & $17.2 \pm 5.2$ & $6 \pm 1.4$ & $6.9 \pm 2.9$ \\
\hline & cold & $49 \pm 9 * * *$ & $47.1 \pm 5.1$ & $38.4 \pm 7.5^{* * *}$ & $42.3 \pm 8.9 * * *$ & $20.7 \pm 12.8$ & $33.0 \pm 1.0 * *$ & $16.4 \pm 8.5$ & $29.7 \pm 5.4 * * *$ \\
\hline \multirow[t]{2}{*}{ mg fructose } & control & $2.1 \pm 0.5$ & $1.7 \pm 0.3$ & $0.8 \pm 0.2$ & $1.1 \pm 0.2$ & $2.1 \pm 0.4$ & $2.8 \pm 0.4$ & $3.5 \pm 0.3$ & $1.8 \pm 0.2$ \\
\hline & cold & $9.0 \pm 1.0 * * *$ & $5.8 \pm 0.6 * * *$ & $6 \pm 1 * * *$ & $4.1 \pm 0.4 * * *$ & $7.5 \pm 1.1 * * *$ & $6.3 \pm 0.8 * * *$ & $7.1 \pm 0.6 * * *$ & $5.1 \pm 0.4 * * *$ \\
\hline \multirow[t]{2}{*}{ mg glucose } & control & $5.8 \pm 0.7$ & $4.5 \pm 0.4$ & $4.7 \pm 0.6$ & $6 \pm 0.8$ & $8.9 \pm 0.9$ & $8.2 \pm 1.1$ & $7.2 \pm 0.5$ & $7.4 \pm 0.5$ \\
\hline & cold & $10.4 \pm 1.1 * * *$ & $9.5 \pm 0.7 * * *$ & $9.3 \pm 1 * * *$ & $8.8 \pm 0.4 * * *$ & $11.6 \pm 0.9 * *$ & $10.6 \pm 0.8^{*}$ & $11.6 \pm 1.2 * * *$ & $11.6 \pm 0.6^{* * *}$ \\
\hline \multirow[t]{2}{*}{ mg sucrose } & control & nd & nd & nd & nd & $1.8 \pm 0.5$ & $1.0 \pm 0.3$ & $2.1 \pm 0.5$ & $2.3 \pm 0.4$ \\
\hline & cold & $0.8 \pm 0.4^{* * *}$ & $1 \pm 0.24 * * *$ & $1.3 \pm 0.3 * * *$ & $1 \pm 0.2 * * *$ & $3.4 \pm 0.3 * *$ & $4.4 \pm 0.3^{* * *}$ & $5.2 \pm 0.4^{* *}$ & $5.6 \pm 0.3 * * *$ \\
\hline \multirow[t]{2}{*}{ mg maltose } & control & nd & nd & $0.4 \pm 0.1$ & nd & $1.2 \pm 0.3$ & $0.5 \pm 0.2$ & $1.3 \pm 0.3$ & $0.7 \pm 0.2$ \\
\hline & cold & $1.2 \pm 0.2 * * *$ & $3.2 \pm 0.3 * * *$ & $2.9 \pm 0.6 * * *$ & $3.3 \pm 0.2 * * *$ & $1.7 \pm 0.2$ & $2.7 \pm 0.4 * * *$ & $2.7 \pm 0.3 * * *$ & $5.1 \pm 0.6 * * *$ \\
\hline
\end{tabular}


Table 2. Effect of cold treatment on the fatty acid composition (mol\%), double bond index (DBI) and percentage of unsaturation (\%unsat) of lipid classes from leaves of winter wheat (Mv Hombár and Mv8), spring wheat (TC33 and TC19) spring oat (Kwant and Mv Pehely), winter barley (Petra) and spring barley (Jubilant). Data represent mean values $\pm \mathrm{SD} ; *{ }^{* *}$ and $* * *$ denote significant differences from control at the $0.05,0.01$ and 0.005 levels, respectively $(n=3)$.

\begin{tabular}{|c|c|c|c|c|c|c|c|c|c|}
\hline fraction & treatment & 16:0 & $16: 1$ & 18:0 & 18:1 & $18: 2$ & $18: 3$ & DBI & unsat $\%$ \\
\hline \multirow[t]{15}{*}{ MGDG } & control Mv Hombár & $1.1 \pm 0.5$ & nd & $0.1 \pm 0.1$ & $0.2 \pm 0.1$ & $2.5 \pm 1.1$ & $96.1 \pm 5.1$ & $293.5 \pm 7.9$ & $98.8 \pm 2$ \\
\hline & cold Mv Hombár & $1.3 \pm 0.4$ & nd & $0.5 \pm 0.1 * *$ & $0.3 \pm 0.1$ & $1.7 \pm 1$ & $96.2 \pm 2.6$ & $292.3 \pm 6.4$ & $98.2 \pm 2.2$ \\
\hline & control Mv 8 & $1.6 \pm 0.6$ & nd & $0.5 \pm 0.1$ & $0.3 \pm 0.3$ & $3.2 \pm 1.42$ & $94.4 \pm 5.7$ & $289.8 \pm 7.5$ & $97.9 \pm 2.1$ \\
\hline & control TC33 & $1.9 \pm 0.4$ & nd & $0.9 \pm 0.2$ & $0.1 \pm 0.1$ & $2.4 \pm 1.2$ & $94.7 \pm 6.2$ & $289.1 \pm 7.1$ & $97.2 \pm 1.6$ \\
\hline & cold TC33 & $1.8 \pm 0.5$ & nd & $0.7 \pm 0.1$ & $0.6 \pm 0.3$ & $1.5 \pm 0.7$ & $95.3 \pm 4.7$ & $289.6 \pm 6.5$ & $97.5 \pm 1.4$ \\
\hline & control TC19 & $1.5 \pm 0.6$ & nd & $0.4 \pm 0.2$ & $0.4 \pm 0.1$ & $2.8 \pm 1.2$ & $94.9 \pm 4.5$ & $290.5 \pm 7.8$ & $98.1 \pm 1.2$ \\
\hline & cold TC19 & $2 \pm 0.5$ & nd & $0.8 \pm 0.2 * *$ & $0.5 \pm 0.2$ & $1.5 \pm 0.8$ & $95.1 \pm 3.9$ & $288.9 \pm 5.2$ & $97.2 \pm 2.9$ \\
\hline & control Kwant & $1.4 \pm 0.4$ & nd & $0.2 \pm 0.1$ & $0.9 \pm 0.3$ & $2.8 \pm 1.2$ & $94.8 \pm 5.6$ & $290.7 \pm 8.4$ & $98.4 \pm 2.4$ \\
\hline & cold Kwant & $2.3 \pm 0.6$ & nd & $1.7 \pm 0.15 * * *$ & $0.5 \pm 0.1$ & $0.9 \pm 0.6$ & $94.6 \pm 4.6$ & $286.1 \pm 7.5$ & $96 \pm 3.3$ \\
\hline & control Mv Pehely & $1.6 \pm 0.5$ & nd & $2.1 \pm 0.1$ & $1 \pm 0.6$ & $4.2 \pm 1.3$ & $90.9 \pm 4.3$ & $282 \pm 6.1$ & $96.3 \pm 2.9$ \\
\hline & cold Mv Pehely & $1.4 \pm 0.5$ & nd & $0.5 \pm 0.1 * * *$ & $0.5 \pm 0.2$ & $2.1 \pm 1.1 * *$ & $95.5 \pm 5.7$ & $291.1 \pm 5.2$ & $98.1 \pm 2.1$ \\
\hline & control Petra & $2.4 \pm 0.4$ & nd & $0.9 \pm 0.1$ & $0.5 \pm 0.4$ & $3.7 \pm 1.3$ & $92.5 \pm 2.4$ & $285.4 \pm 4.8$ & $96.7 \pm 2.4$ \\
\hline & cold Petra & $2.6 \pm 0.4$ & nd & $1.3 \pm 0.2 * * *$ & $0.9 \pm 0.3$ & $2.5 \pm 1.3$ & $92.7 \pm 4.3$ & $284 \pm 7.6$ & $96.1 \pm 2.5$ \\
\hline & control Jubilant & $2.3 \pm 0.5$ & nd & $4.3 \pm 0.1$ & $0.4 \pm 0.3$ & $3.5 \pm 1.4$ & $89.4 \pm 5.4$ & $275.7 \pm 5.3$ & $93.4 \pm 3$ \\
\hline & cold Jubilant & $3.5 \pm 0.7$ & nd & $1.3 \pm 0.2 * * *$ & $1 \pm 0.5$ & $2.6 \pm 1.3$ & $91.6 \pm 4.8$ & $281 \pm 7.1$ & $95.2 \pm 3.5$ \\
\hline \multirow[t]{15}{*}{$\overline{\text { DGDG }}$} & control Mv Hombár & $10.5 \pm 1.4$ & nd & $1.3 \pm 0.6$ & $0.6 \pm 0.2$ & $2.4 \pm 1$ & $85.2 \pm 4.7$ & $261 \pm 5.7$ & $88.2 \pm 2.6$ \\
\hline & control Mv 8 & $10.1 \pm 1.6$ & nd & $1.2 \pm 0.5$ & $0.6 \pm 0.2$ & $2.9 \pm 1.4$ & $85.3 \pm 4.2$ & $262.3 \pm 7.5$ & $88.7 \pm 3.5$ \\
\hline & cold Mv 8 & $10 \pm 1.2$ & nd & $2.3 \pm 0.6$ & $1.4 \pm 0.6$ & $2 \pm 1.1$ & $84.3 \pm 4.6$ & $258.4 \pm 8.4$ & $87.7 \pm 4.3$ \\
\hline & control TC33 & $9.6 \pm 1.3$ & nd & $1.1 \pm 0.3$ & $1.2 \pm 0.3$ & $2.4 \pm 1.3$ & $85.7 \pm 6.2$ & $263.1 \pm 4.9$ & $89.3 \pm 3$ \\
\hline & cold TC33 & $9.2 \pm 1.1$ & nd & $1.6 \pm 0.7$ & $0.6 \pm 0.3$ & $1.9 \pm 1$ & $86.6 \pm 5.4$ & $264.4 \pm 5.6$ & $89.2 \pm 5$ \\
\hline & control TC19 & $9.8 \pm 1.5$ & nd & $1.3 \pm 0.5$ & $1.2 \pm 0.2$ & $3.3 \pm 1.5$ & $84.4 \pm 4.1$ & $261 \pm 5.4$ & $88.9 \pm 4.6$ \\
\hline & cold TC19 & $9.8 \pm 2.1$ & nd & $2 \pm 0.6$ & $1.1 \pm 0.1$ & $2.3 \pm 1.2$ & $84.9 \pm 4.7$ & $260.4 \pm 5.5$ & $88.3 \pm 3.2$ \\
\hline & control Kwant & $9.2 \pm 1.9$ & nd & $0.8 \pm 0.5$ & $1.4 \pm 0.1$ & $2.6 \pm 1.1$ & $86 \pm 3.3$ & $264.5 \pm 5.7$ & $89.9 \pm 3.6$ \\
\hline & cold Kwant & $9.5 \pm 1.6$ & nd & $1.1 \pm 0.38$ & $1.7 \pm 0.1$ & $2.1 \pm 1.1$ & $85.7 \pm 2.6$ & $262.9 \pm 4.5$ & $89.5 \pm 4.2$ \\
\hline & control Mv Pehely & $10.1 \pm 2.3$ & nd & $2.2 \pm 0.6$ & $1.7 \pm 0.2$ & $3.9 \pm 1.3$ & $82 \pm 2.3$ & $255.7 \pm 6.6$ & $87.7 \pm 2.5$ \\
\hline & cold Mv Pehely & $9.8 \pm 1.7$ & nd & $1 \pm 0.4$ & $1.3 \pm 0.4$ & $2.1 \pm 1.1$ & $85.8 \pm 2.4$ & $262.8 \pm 6.3$ & $89.1 \pm 3.2$ \\
\hline & control Petra & $10.9 \pm 1.3$ & nd & $1.5 \pm 0.5$ & $0.9 \pm 0.2$ & $3.2 \pm 1.1$ & $83.4 \pm 4.2$ & $257.7 \pm 7.2$ & $87.6 \pm 3.5$ \\
\hline & cold Petra & $11.2 \pm 1.7$ & nd & $2.8 \pm 0.6$ & $0.9 \pm 0.2$ & $2.5 \pm 1.3$ & 82. $6 \pm 2.4$ & $253.6 \pm 7.5$ & $86 \pm 4.7$ \\
\hline & control Jubilant & $10.9 \pm 1.2$ & nd & $1.5 \pm 0.4$ & $1.3 \pm 0.3$ & $3.6 \pm 1.4$ & $82.6 \pm 2.6$ & $256.4 \pm 8.2$ & $87.6 \pm 4.1$ \\
\hline & cold Jubilant & $11.5 \pm 1.4$ & nd & $1.9 \pm 0.4$ & $1 \pm 0.1$ & $3.2 \pm 1.2$ & $82.5 \pm 2.5$ & $254.8 \pm 5.6$ & $86.7 \pm 3.5$ \\
\hline \multirow[t]{13}{*}{$\overline{\mathbf{P E}}$} & control Mv Hombár & $30.4 \pm 2.5$ & nd & $11.2 \pm 0.9$ & $3.2 \pm 1.2$ & $29.1 \pm 2.6$ & $26.1 \pm 1.8$ & $139.7 \pm 5.1$ & $58.4 \pm 2.4$ \\
\hline & cold Mv Hombár & $22.4 \pm 2.2 * *$ & nd & $8.5 \pm 1.1 * *$ & $4.5 \pm 0.5$ & $34.1 \pm 3.5$ & $30.6 \pm 1.3 *$ & $164.4 \pm 4.9 * * *$ & $69.2 \pm 4.5$ \\
\hline & cold TC33 & $23.4 \pm 3$ & nd & $3.4 \pm 0.1 * * *$ & $4.4 \pm 1.2$ & $28.8 \pm 3.4 * *$ & $40 \pm 2.5 * * *$ & $182.1 \pm 5.2 * * *$ & $73.2 \pm 3.2$ \\
\hline & control TC19 & $25.9 \pm 2.4$ & nd & $4.7 \pm 1.2$ & $4.1 \pm 1.4$ & $36.3 \pm 3.3$ & $29.2 \pm 1.1$ & $164 \pm 4.9$ & $69.5 \pm 2.4$ \\
\hline & cold TC19 & $21.8 \pm 2.2$ & nd & $5.6 \pm 1.1$ & $4.2 \pm 1$ & $29.3 \pm 2.7 *$ & $41.1 \pm 2.7 * * *$ & $186.1 \pm 6 * * *$ & $73.1 \pm 3.2$ \\
\hline & control Kwant & $22.1 \pm 2.6$ & nd & $2.3 \pm 0.2$ & $5.3 \pm 1.2$ & $34 \pm 4.6$ & $36.4 \pm 1.2$ & $182.3 \pm 4.9$ & $75.6 \pm 2.9$ \\
\hline & cold Kwant & $20.2 \pm 2.5$ & nd & $2.5 \pm 0.2$ & $4 \pm 1.5$ & $34.6 \pm 3.3$ & 38. $7 \pm 1.9$ & $189.3 \pm 5.6$ & $77.3 \pm 4.2$ \\
\hline & control Mv Pehely & $25.6 \pm 2.8$ & nd & $4.8 \pm 0.5$ & $6.2 \pm 1.2$ & $35.5 \pm 2.3$ & $27.7 \pm 1.2$ & $160.5 \pm 4.1$ & $69.5 \pm 3.2$ \\
\hline & cold Mv Pehely & $24.7 \pm 1.6$ & nd & $5.1 \pm 0.9$ & $4.5 \pm 1.3$ & $30.5 \pm 3.7$ & $35.3 \pm 1.4^{* * *}$ & $171.3 \pm 5.6$ & $70.2 \pm 3.7$ \\
\hline & control Petra & $29.5 \pm 2.3$ & nd & $2.3 \pm 0.7$ & $2.8 \pm 1.4$ & $32.7 \pm 2.3$ & $32.7 \pm 2.1$ & $166.3 \pm 4.2$ & $68.2 \pm 2.6$ \\
\hline & cold Petra & $30.6 \pm 2.7$ & nd & $3.7 \pm 0.5$ & $2 \pm 0.1$ & $31.2 \pm 2.2$ & $32.5 \pm 2$ & $162 \pm 6.8$ & $65.7 \pm 3$ \\
\hline & control Jubilant & $35.1 \pm 2.3$ & nd & $3.6 \pm 0.7$ & $4 \pm 1.4$ & $31.3 \pm 2.4$ & $26 \pm 2.7$ & $144.5 \pm 4.6$ & $61.3 \pm 3.5$ \\
\hline & cold Jubilant & $30.2 \pm 1.9$ & nd & $3 \pm 0.5$ & $2 \pm 1.3$ & $32 \pm 2.8$ & $32.9 \pm 2.1 * * *$ & $164.5 \pm 5.1 * * *$ & $66.8 \pm 2.4$ \\
\hline \multirow[t]{16}{*}{$\overline{P G}$} & control Mv Hombár & $12.4 \pm 1$ & $23.4 \pm 1.74$ & $1.6 \pm 0.1$ & $1.6 \pm 1.1$ & $4.1 \pm 1.4$ & $56.9 \pm 1.3$ & $180.4 \pm 4.3$ & $62.6 \pm 3.5$ \\
\hline & cold Mv Hombár & $18.2 \pm 1.6^{* * *}$ & $14.1 \pm 1.1 * * *$ & $1.7 \pm 0.5$ & $1.3 \pm 0.1$ & $4.8 \pm 0.1$ & $60 \pm 2.2$ & $190.9 \pm 4.4^{*}$ & $66.1 \pm 2.6$ \\
\hline & control Mv 8 & $15.4 \pm 1.3$ & $22.7 \pm 2.2$ & $2.9 \pm 1$ & $1.6 \pm 0.1$ & $6.1 \pm 1.2$ & $51.4 \pm 3.1$ & $168 \pm 5.1$ & $59.1 \pm 3.2$ \\
\hline & cold Mv 8 & $18.9 \pm 1.1 * * *$ & $15.8 \pm 1.5^{* * *}$ & $3.3 \pm 1.2$ & $2.2 \pm 1$ & $5.4 \pm 1.5$ & $54.4 \pm 2$ & $176.2 \pm 4.3$ & $62 \pm 3.4$ \\
\hline & control TC33 & $16.1 \pm 1.1$ & $29.9 \pm 2.3$ & $2.5 \pm 1.1$ & $1.3 \pm 0.7$ & $5.5 \pm 1.4$ & $44.7 \pm 3$ & $146.5 \pm 5.6$ & $51.6 \pm 2.2$ \\
\hline & cold TC33 & $17.9 \pm 1.8$ & $18.9 \pm 1.8 * * *$ & $3.5 \pm 1$ & $2 \pm 0.9$ & $5.3 \pm 1.1$ & $52.3 \pm 1.5^{* * *}$ & $169.6 \pm 4.1 * * *$ & $59.6 \pm 2.9 * * *$ \\
\hline & control TC19 & $14.7 \pm 1.4$ & $27.1 \pm 2.5$ & $2.5 \pm 1$ & $1.8 \pm 1.1$ & $6.1 \pm 1.5$ & $47.9 \pm 1.3$ & $157.7 \pm 4.1$ & $55.8 \pm 4.4$ \\
\hline & cold TC19 & $19.3 \pm 1.3 * * *$ & $19.3 \pm 1.2 * * *$ & $4.5 \pm 1.3$ & $2.4 \pm 1.1$ & $5 \pm 1.2$ & $49.5 \pm 1.4$ & $161 \pm 6.1$ & $56.9 \pm 4.8$ \\
\hline & control Kwant & $16.5 \pm 1.4$ & $25 \pm 2.4$ & $2.8 \pm 1.2$ & $1.9 \pm 1.4$ & $3.9 \pm 1.1$ & $50 \pm 2.3$ & $159.7 \pm 4.2$ & $55.8 \pm 2.8$ \\
\hline & cold Kwant & $21.6 \pm 1.2 * * *$ & $22.8 \pm 1.5$ & $2.1 \pm 1.3$ & $2.1 \pm 1.3$ & $4.1 \pm 1.5$ & $47.3 \pm 4.7$ & $152.3 \pm 4.8$ & $53.6 \pm 4.4$ \\
\hline & control Mv Pehely & $20.6 \pm 2.1$ & $25.5 \pm 1$ & $4.8 \pm 1.5$ & $4.1 \pm 2.5$ & $5.4 \pm 1.4$ & $39.6 \pm 2$ & $133.6 \pm 4.6$ & $49 \pm 3.6$ \\
\hline & cold Mv Pehely & $20.3 \pm 1$ & $25.3 \pm 1.1$ & $2 \pm 1.1^{*}$ & $2.2 \pm 1.5$ & $3.9 \pm 1.9$ & $46.3 \pm 2.4 * * *$ & $148.7 \pm 6.7 * *$ & $52.3 \pm 2.5$ \\
\hline & control Petra & $14.3 \pm 1.2$ & $29.4 \pm 1.4$ & $3.3 \pm 1.2$ & $2.4 \pm 1.3$ & $5.2 \pm 0.1$ & $53.2 \pm 1.5$ & $172.4 \pm 4.51$ & $60.8 \pm 3.7$ \\
\hline & cold Petra & $20.7 \pm 2.3 * * *$ & $21.7 \pm 1.2 * * *$ & $8.9 \pm 1.5 * * *$ & $2.5 \pm 1.2$ & $5.1 \pm 1.1$ & $46.6 \pm 2.2 * * *$ & $152.5 \pm 5.3 * *$ & $54.2 \pm 2.1 *$ \\
\hline & control Jubilant & $14.7 \pm 1.6$ & $28.5 \pm 1.4$ & $7.6 \pm 1.4$ & nd & $10.7 \pm 2.3$ & $39.7 \pm 1.9$ & $140.5 \pm 5.2$ & $50.4 \pm 3.3$ \\
\hline & cold Jubilant & $22.4 \pm 1.3^{* * *}$ & $18.1 \pm 1.3^{* * *}$ & $10.4 \pm 1.2 *$ & $5.5 \pm 1.3$ & $7.2 \pm 3.4$ & $41.2 \pm 1.5$ & $143.5 \pm 6.2$ & $53.9 \pm 2.4$ \\
\hline
\end{tabular}


5Table 3. Correlation analysis on the parameters of winter wheat (Mv Hombár and Mv8), spring wheat (TC33 and TC19) spring oat (Kwant and Mv Pehely), 6 winter barley (Petra) and spring barley (Jubilant) under control conditions. Strong correlations significant at 0.05 are highlighted.

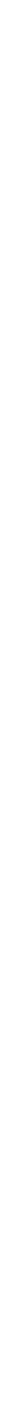


5Table 4. Correlation analysis on the parameters of winter wheat (Mv Hombár and Mv8), spring wheat (TC33 and TC19) spring oat (Kwant and Mv Pehely), ${ }^{6}$ winter barley (Petra) and spring barley (Jubilant) after $12 \mathrm{~d}$ cold treatment at $5^{\circ} \mathrm{C}$. Strong correlations significant at 0.05 are highlighted. 
Fig. 1. Accumulation of polyamines, putrescine (PUT), cadaverin (CAD), spermidine (SPD) and spermine (SPN) in the leaves of winter wheat (Mv Hombár and Mv8), spring wheat (TC33 and TC19) spring oat (Kwant and Mv Pehely), winter barley (Petra) and spring barley (Jubilant) after cold treatment. *,** and $* * *$ denote significant differences from the control of the same day at the $0.05,0.01$ and 0.001 levels, respectively.

Fig. 2. Changes in the levels of free and bound salicylic acid (A), and free and bound (B) ortho-hydroxycinnamic acid in the leaves of winter wheat (Mv Hombár and Mv8), spring wheat (TC33 and TC19) spring oat (Kwant and Mv Pehely), winter barley (Petra) and spring barley (Jubilant) after cold treatment. $*, * *$ and $* * *$ denote significant differences from the control of the same day at the $0.05,0.01$ and 0.001 levels, respectively.

Fig. 3. Changes in abscisic acid content in the leaves of winter wheat (Mv Hombár and Mv8), spring wheat (TC33 and TC19) spring oat (Kwant and Mv Pehely), winter barley (Petra) and spring barley (Jubilant) after cold treatment. $* *$ and $* * *$ denote significant differences from the control of the same day at the $0.05,0.01$ and 0.001 levels, respectively. 
Fig. 1. Accumulation of polyamines, putrescine (PUT), cadaverin (CAD), spermidine (SPD) and spermine (SPN) in the leaves of winter wheat (Mv Hombár and Mv8), spring wheat (TC33 and TC19) spring oat (Kwant and Mv Pehely), winter barley (Petra) and spring barley (Jubilant) after cold treatment. *, ** and $* * *$ denote significant differences from the control of the same day at the $0.05,0.01$ and 0.001 levels, respectively.

$256 \times 136 \mathrm{~mm}(150 \times 150 \mathrm{DPI})$ 




Fig. 2. Changes in the levels of free and bound salicylic acid (A), and free and bound (B) orthohydroxycinnamic acid in the leaves of winter wheat (Mv Hombár and Mv8), spring wheat (TC33 and TC19) spring oat (Kwant and Mv Pehely), winter barley (Petra) and spring barley (Jubilant) after cold treatment. *, $* *$ and $* * *$ denote significant differences from the control of the same day at the $0.05,0.01$ and 0.001 levels, respectively. $209 \times 190 \mathrm{~mm}(150 \times 150$ DPI $)$ 


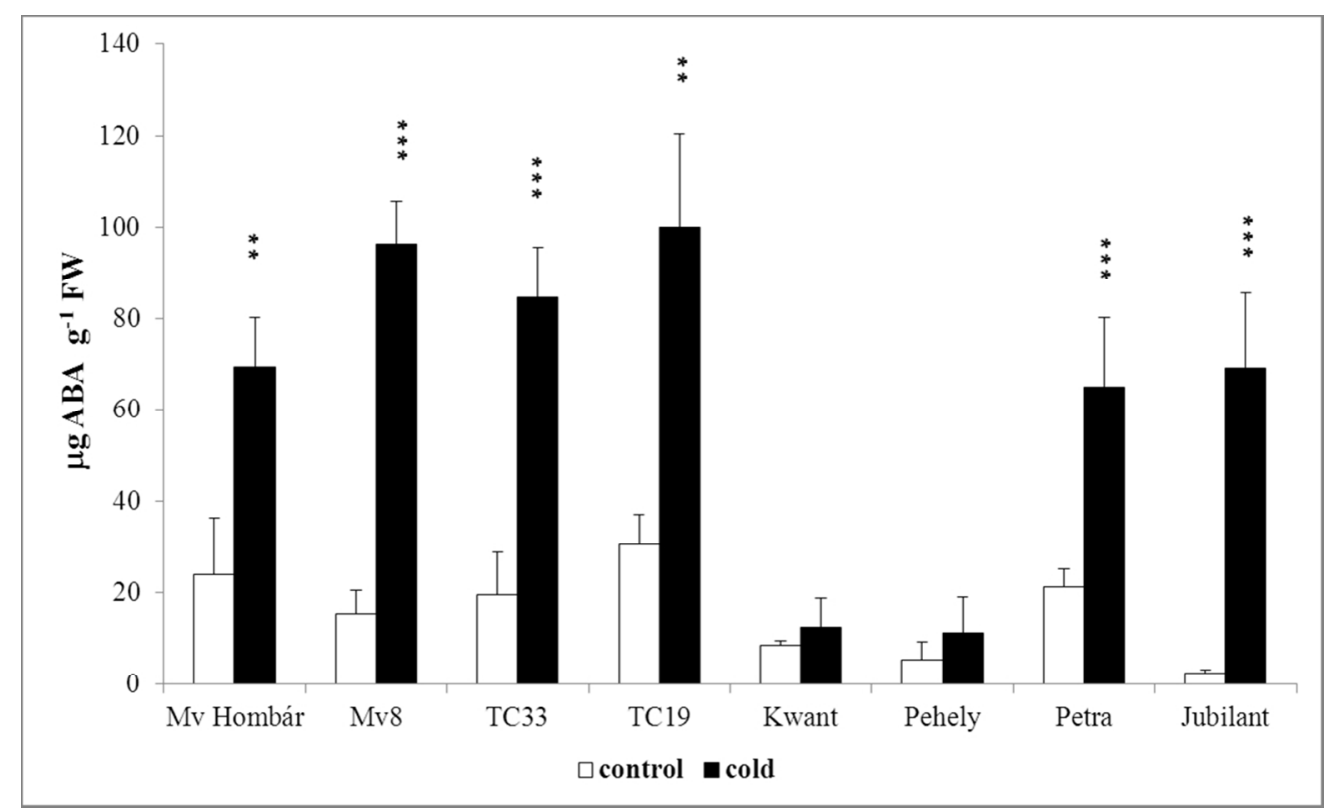

Fig. 3. Changes in abscisic acid content in the leaves of winter wheat (Mv Hombár and Mv8), spring wheat (TC33 and TC19) spring oat (Kwant and Mv Pehely), winter barley (Petra) and spring barley (Jubilant) after cold treatment. $* *$ and $* * *$ denote significant differences from the control of the same day at the $0.05,0.01$ and 0.001 levels, respectively. $197 \times 119 \mathrm{~mm}(150 \times 150 \mathrm{DPI})$ 